\title{
Efficacy of Souvenaid in Mild Alzheimer's Disease: Results from a Randomized, Controlled Trial
}

\author{
Philip Scheltens ${ }^{\mathrm{a}, *}$, Jos W.R. Twisk ${ }^{\mathrm{b}}$, Rafael Blesa ${ }^{\mathrm{c}}$, Elio Scarpini ${ }^{\mathrm{d}}$, Christine A.F. von Arnim ${ }^{\mathrm{e}}$, \\ Anke Bongers ${ }^{\mathrm{f}}$, John Harrison ${ }^{\mathrm{g}, \mathrm{h}}$, Sophie H.N. Swinkels ${ }^{\mathrm{f}}$, Cornelis J. Stam ${ }^{\mathrm{i}}$, Hanneke de Waal ${ }^{\mathrm{a}}$, \\ Richard J. Wurtman ${ }^{\mathrm{j}}$, Rico L. Wieggers ${ }^{\mathrm{f}}$, Bruno Vellas ${ }^{\mathrm{k}}$ and Patrick J.G.H. Kamphuis ${ }^{\mathrm{f}}$ \\ ${ }^{\mathrm{a}}$ Alzheimer Center, VU University Medical Center, Amsterdam, The Netherlands \\ ${ }^{\mathrm{b}}$ Department of Clinical Epidemiology and Biostatistics, VU University Medical Center, Amsterdam, \\ The Netherlands \\ ${ }^{\mathrm{c}}$ Hospital de la Sta Creu i St. Pau, Barcelona, Spain \\ ${ }^{\mathrm{d}}$ Ospedale Maggiore Policlinico IRCCS, University of Milan, Milan, Italy \\ ${ }^{\mathrm{e}}$ Department of Neurology, Ulm University, Ulm, Germany \\ ${ }^{\mathrm{f}}$ Nutricia Advanced Medical Nutrition, Danone Research, Centre for Specialised Nutrition, Wageningen, \\ The Netherlands \\ $\mathrm{g}_{\text {Metis Cognition Ltd, Kilmington, UK }}$ \\ ${ }^{\mathrm{h}}$ Imperial College, London, UK \\ ${ }^{\mathrm{i}}$ Department of Clinical Neurophysiology, VU University Medical Center, Amsterdam, The Netherlands \\ ${ }^{\mathrm{j} D e p a r t m e n t ~ o f ~ B r a i n ~ a n d ~ C o g n i t i v e ~ S c i e n c e s, ~ M a s s a c h u s e t t s ~ I n s t i t u t e ~ o f ~ T e c h n o l o g y, ~ C a m b r i d g e, ~ M A, ~ U S A ~}$ \\ ${ }^{\mathrm{k}}$ Gerontopole, INSERM U 1027, Toulouse, France
}

Accepted 1 June 2012

\begin{abstract}
Souvenaid aims to improve synapse formation and function. An earlier study in patients with Alzheimer's disease (AD) showed that Souvenaid increased memory performance after 12 weeks in drug-naïve patients with mild AD. The Souvenir II study was a 24-week, randomized, controlled, double-blind, parallel-group, multi-country trial to confirm and extend previous findings in drug-naïve patients with mild AD. Patients were randomized 1:1 to receive Souvenaid or an iso-caloric control product once daily for 24 weeks. The primary outcome was the memory function domain Z-score of the Neuropsychological Test Battery (NTB) over 24 weeks. Electroencephalography (EEG) measures served as secondary outcomes as marker for synaptic connectivity. Assessments were done at baseline, 12 , and 24 weeks. The NTB memory domain Z-score was significantly increased in the active versus the control group over the 24-week intervention period ( $p=0.023$; Cohen's $\mathrm{d}=0.21$; $95 \%$ confidence interval $[-0.06]-[0.49])$. A trend for an effect was observed on the NTB total composite z-score $(p=0.053)$. EEG measures of functional connectivity in the delta band were significantly different between study groups during 24 weeks in favor of the active group.
\end{abstract}

\footnotetext{
*Correspondence to: Prof. Philip Scheltens, Department of Neurology and Alzheimer Center, VU University Medical Center, De Boelelaan 1117, Amsterdam 1081 HV, The Netherlands. Tel.: +31 20444 0816; Fax: +31 20 4440715; E-mail: p.scheltens@vumc.nl.
} 
Compliance was very high $(96.6 \%$ [control] and $97.1 \%$ [active]). No difference between study groups in the occurrence of (serious) adverse events. This study demonstrates that Souvenaid is well tolerated and improves memory performance in drugnaïve patients with mild AD. EEG outcomes suggest that Souvenaid has an effect on brain functional connectivity, supporting the underlying hypothesis of changed synaptic activity.

Keywords: Alzheimer's disease, dietary management, medical food, membrane phosphatide synthesis, nutritional intervention, randomized clinical trial, synapse formation, synaptic activity

Supplementary data available online: http://dx.doi.org/10.3233/JAD-2012-121189

\section{INTRODUCTION}

The main pathological hallmarks of Alzheimer's disease (AD) are known to include the accumulation of amyloid- $\beta$ plaques and neurofibrillary tangles due to abnormal protein processing. From the very start of the disease process, there is synaptic loss and reduced synaptic activity/connectivity in specific brain areas [1, 2]. In addition, synapse loss is considered to be the most direct structural correlate of cognitive performance in $\mathrm{AD}$ [3], compared with the number of plaques or tangles, or degree of neuronal loss [2]. Synapses consist principally of neuronal membranes, and the neuronal and synaptic loss observed in $\mathrm{AD}$ has been linked to the degeneration of these membranes $[4,5]$. This degeneration may account for the disturbed organization of brain networks, and support for this has been found in human studies showing impaired functional brain connectivity in patients with AD compared with controls $[6,7]$. As such, synaptic loss and membranerelated pathology provide potentially useful targets for intervention in AD.

Administration of nutrients that are precursors for the abundant phosphatides in neuronal membranes can, in experimental animals, increase the formation and cellular levels of brain phosphatides [8]. In vitro and in vivo studies have demonstrated that supplementation with docosahexaenoic acid (DHA) or eicosapentaenoic acid (EPA), uridine (as uridine monophosphate [UMP]), and choline not only increase phosphatide synthesis [8], but also increase neurite outgrowth, levels of specific pre- or post-synaptic proteins, and the number of dendritic spines, all prerequisites for new synapse formation [9, 10]. Furthermore, B vitamins as co-factors enhance endogenous precursor synthesis via the regeneration of methyl groups, therefore affecting the availability of precursors [11], and potentially synaptogenesis. The administration of combinations of phospholipid synthesis-promoting nutrients has also been shown to enhance cognitive function and neurotransmitter release in animal models $[12,13]$.
These observations suggested that administering specific nutrients could increase synapse formation and synaptic function, and could potentially ameliorate cognitive disturbances of patients with $\mathrm{AD}$ [14]. This hypothesis formed the basis for the development of Souvenaid ${ }^{\circledR}$ (Nutricia N.V., Zoetermeer, The Netherlands), a product intended as a medical food* for oral consumption under medical supervision with the purpose of addressing disease-specific nutrient requirements. Souvenaid contains the nutritional combination Fortasyn ${ }^{\mathrm{TM}}$ Connect, which includes precursors and other specific nutrients required to enhance neuronal membrane formation (Table 1).

Synaptic dysfunction is a pathological process involved in the early stages of $\mathrm{AD}[1,2]$. Targeting synaptic loss and membrane-related pathology might therefore be most efficacious at this stage. Furthermore, it is commonly accepted in the field that interventions must be administered as early as possible. Therefore, the efficacy and tolerability of Souvenaid was first tested in a double-blind, controlled, multi-country, proof-of-concept study (Souvenir I study, Dutch Trial Register \#ISRCTN72254645) involving 225 drug-naïve patients with mild AD (MiniMental State Examination [MMSE] scores, 20-26). In that study, Souvenaid was well tolerated and improved 12-week memory performance as measured by delayed verbal recall testing, the co-primary endpoint of the study. The other co-primary outcome (Alzheimer's Disease Assessment Scale-cognitive

\footnotetext{
*A medical food is (in the USA) defined in 21 U.S.C. $\$ 360 e e(b)(3)$ as " a food which is formulated to be consumed or administered enterally under the supervision of a physician and which is intended for the specific dietary management of a disease or condition for which distinctive nutritional requirements, based on recognizable scientific principles, are established by medical evaluation"1. A comparable definition exists in the harmonized legislation of the European Union (cf. Article 1,2(b) of Commission Directive 1999/21/EC of 25 March 1999 on dietary foods for special medical purposes.

1 US Food and Drug Administration. Frequently Asked Questions About Medical Foods. College Park, MD: FDA, Center for Food Safety and Applied Nutrition, US Department of Health and Human Services; 2007.
} 
Table 1

Nutritional composition of Fortasyn ${ }^{\mathrm{TM}}$ Connect, the nutrient combination in Souvenaid

\begin{tabular}{lc}
\hline Component & $\begin{array}{c}\text { Amount per } \\
\text { daily dose* }\end{array}$ \\
\hline Eicosapentaenoic acid, mg & 300 \\
Docosahexaenoic acid, mg & 1200 \\
Phospholipids, mg & 106 \\
Choline, mg & 400 \\
Uridine monophosphate, mg & 625 \\
Vitamin E (alpha-tocopherol equivalents), mg & 40 \\
Vitamin C, mg & 80 \\
Selenium, $\mu \mathrm{g}$ & 60 \\
Vitamin B12, $\mu \mathrm{g}$ & 3 \\
Vitamin B6, mg & 1 \\
Folic acid, $\mu \mathrm{g}$ & 400 \\
\hline
\end{tabular}

*Souvenaid (125 mL [125 kcal] daily dose) contains Fortasyn Connect. Souvenaid is a registered trademark of Nutricia N.V. Fortasyn is a trademark of Nutricia N.V.

subscale [ADAS-cog]) remained unchanged [15]. The results of the Souvenir I study provided a first indication to support the hypothesis above; however, no biomarkers of synaptic activity and connectivity were measured to further validate this hypothesis.

Although it is not possible to quantify synaptic density directly in humans, electrical brain activity can be measured directly at the skull with electroencephalography (EEG). The resulting time series are a compound of synaptic activity in the cerebral cortex underneath the EEG electrodes. Newer techniques for the analysis of EEG signals allow us to study whether changes in synaptic activity can be detected as changes in functional connectivity [16].

It has been reported previously that the ADAS-cog as a tool for measuring cognition may not be adequate to detect changes in patients with milder stages of $\mathrm{AD}$ [17], something which is in line with the observations of the Souvenir I study $[15,18]$. The use of a Neuropsychological Test Battery (NTB) is increasingly seen as a promising method to detect changes in cognition in early $\mathrm{AD}$ [17]. In addition, early $\mathrm{AD}$ is characterized by deficits in episodic memory [19] and the NTB has shown to be able to detect changes in memory performance [20].

Taking into account all of the above, the 'Souvenir II' study was designed to evaluate the effect of Souvenaid on memory in drug-naive patients with mild $A D(M M S E \geq 20$ ), using an intervention period of 24 weeks and the NTB memory domain score as the primary outcome measure. EEG was included as a secondary parameter to substantiate the biological effect on synaptic function.

\section{MATERIALS AND METHODS}

\section{Patients}

The Souvenir II study was a 24-week, randomized, controlled, double-blind, parallel-group, multi-country, trial to assess the efficacy and tolerability of Souvenaid in drug-naive patients with mild AD. Patients aged $\geq 50$ years with a diagnosis of probable AD according to the National Institute of Neurological and Communicative Disorders and Stroke and the Alzheimer's Disease and Related Disorders Association (NINCDS-ADRDA) criteria [21], an MMSE score of $\geq 20$, and a responsible caregiver were eligible for inclusion if a recent magnetic resonance imaging (MRI) or computed tomography (CT) scan had shown no evidence of any other potential causes of dementia.

Exclusion criteria included diagnosis of a significant neurological disease other than $\mathrm{AD}$; a Geriatric Depression Scale (15-item) score of $>6$; use of a cholinesterase inhibitor or NMDA-receptor antagonist within 3 months prior to baseline; use of omega-3 fatty acid containing supplements or regular consumption of oily fish (>twice/week) within 2 months prior to baseline; use of atropine, scopolamine, tolterodine, hyoscyamine, biperiden, benztropine, trihexyphenidyl, oxybutynin, antipsychotics, vitamins B, $\mathrm{C}$, and/or E (>200\% of the recommended daily intake), consumption of high energy and/or high protein nutritional supplements, a change in dose of lipid-lowering medications, antidepressants, antihypertensives, or the use of other investigational products within 1 month prior to baseline; excessive alcohol intake or drug abuse; nursing home institutionalization; or investigator uncertainty regarding the willingness or ability of the patient to comply with the protocol.

\section{Procedures}

Participants were recruited from 27 AD centers: The Netherlands (9 centers), Germany (5 centers), Belgium (4 centers), Spain ( 3 centers), Italy ( 3 centers), and France ( 3 centers). Written informed consent was obtained from patients and caregivers. The Ethics Committees of each participating center reviewed and approved the protocol. The study was conducted in accordance with the Declaration of Helsinki, the International Conference on Harmonisation guidelines for Good Clinical Practice as appropriate for nutritional products, and local legislation of the country in which the research was conducted. The Dutch Trial Registration number for this study is NTR1975. 
Upon entry into the study, patients were randomized $1: 1$ to receive the active product Souvenaid, containing the specific nutrient combination Fortasyn Connect (DHA, EPA, phospholipids, choline, UMP, vitamin B12, B6, and folate, vitamins $\mathrm{C}$ and $\mathrm{E}$, and selenium [Table 1]), together with other vitamins, minerals, trace elements and macronutrients, or an iso-caloric control product that lacked Fortasyn Connect, but that was otherwise identical to the active product. Both study products were available as a $125 \mathrm{~mL}$ drink with an identical taste profile and appearance, taken once daily for 24 weeks. Allocation to the study groups was performed using a central randomization procedure in the Electronic Data Capture system, using four different randomization codes (A, B, C, and D). The investigator, study-site staff, Danone Research staff, study staff of the Clinical Research Organisation, patients, and caregivers were all blinded to the study products. The randomization code was not broken until initial statistical modeling of the primary outcome was complete.

Major study parameters were assessed at baseline, 12, and 24 weeks. Adverse events (AEs) and changes in concomitant medication and nutritional supplements were recorded every three weeks.

\section{Assessments}

\section{Primary outcome measure}

The primary outcome measure to assess the effect of Souvenaid on memory performance over 24 weeks was the memory function domain score (z-score) based on the NTB [22]. This domain includes Rey Auditory Verbal Learning Test immediate recall, delayed recall and recognition performance, and Wechsler Memory Scale-revised (WMS-r) verbal paired associates immediate and delayed recall.

\section{Secondary outcome measures}

Secondary outcome measures included the executive function domain score (z-score) based on the WMS-r Digit Span, Trail Making Tests parts A and B (Delis Kaplan Executive Function System ${ }^{\text {TM }}$ condition 2 and condition 4, respectively), Category Fluency, and the Controlled Oral Word Association Test. In addition to these tests, the Souvenir II study NTB consisted of the orientation task of the ADAS-cog and the Letter Digit Substitution Test. Study staff performing the assessments received appropriate training on outcome assessments prior to the start of the study.

Other secondary outcome measures included the total NTB composite score (based on all 12 NTB components), individual item scores from the NTB, assessments of functional ability (Disability Assessment for Dementia scale [DAD]) [23], nutritional blood parameters (plasma vitamin E, erythrocyte DHA and EPA, and homocysteine), and EEG to assess eyes-closed resting-state oscillatory brain activity and functional brain connectivity.

EEG data were available for a subset of subjects, as not all study sites were able to collect high quality EEG data. Relative and absolute power in alpha, beta, theta, and delta frequency bands and peak frequency (i.e., the dominant frequency of the power spectrum [24]) were used to assess oscillatory brain activity. The Phase Lag Index (PLI) in the frequency bands was used as the biomarker of functional connectivity, as it is not sensitive to volume conduction [25]; the higher the mean PLI value, the more brain regions are functionally connected. Extensive EEG protocol and analysis methods are described in the Supplementary data (available online: http://www.j-alz.com/issues/31/vol311.html\#supplementarydata06).

\section{Safety assessments}

Safety assessments included the examination of patient medical history, recording of adverse events, and the monitoring of vital signs and additional laboratory parameters.

\section{Statistical analyses}

Sample size was based on repeated measurement analysis. Using an estimated effect size between active and control groups of 0.4 over 24 weeks, a significance level $(\alpha)$ of 0.05 and power $(\beta)$ of $80 \%$, and assuming a $15 \%$ drop-out rate, a sample size of 226 randomized patients was calculated. A pre-specified, blinded, reestimation of the nuisance parameters was conducted to assess whether the calculated sample size was adequate. The results of this analysis and blind interim safety data were reviewed by an independent Data Monitoring Committee, which recommended continuation of the trial without modification.

Efficacy analyses were performed on the intent-totreat population, defined as all patients randomized. Safety analyses were performed on the all-subjectstreated population, defined as all randomized patients who received at least one dose of study product.

NTB domain z-scores were calculated by averaging the individual NTB item z-scores, which were calculated using the following equation: (individual NTB item score - baseline mean of study group)/baseline standard deviation. 
Changes from baseline in outcome measures were analyzed using a mixed model for repeated measures (MMRM) with SAS ${ }^{\circledR}$ software (SAS Enterprise Guide 4.3 for Windows, SAS Institute Inc., Cary, NC, USA). In a three-level model with random site-specific intercepts and random subject-specific intercepts, group (treatment arm), time (treatment duration), and the group*time interaction were tested and adjusted for baseline values (baseline was included as covariate). The two degrees of freedom (df) contrast describing the difference in trajectories over time between active and control groups was taken as the primary indication of treatment effect during the intervention period. In addition, endpoint contrasts were reported. Sensitivity analyses were performed to check sources of variability and uncertainty of the data.

EEG data (relative and absolute power, PLI in alpha, beta, theta, and delta frequency bands and peak frequency) were analyzed using MMRM ( 2 df contrast) with post-baseline measurements as an outcome. All analyses included baseline and sample frequency as covariates. For the EEG power and PLI data, the modeling approach first examined whether an interaction between treatment and time could be considered constant over six brain areas (left/right fronto-central, left/right temporal, left/right parieto-occipital).

Non-parametric alternatives (e.g., the MannWhitney U test) were used for non-normal distributions that were not sufficiently improved by transformations.

\section{RESULTS}

In total, 259 patients were randomized to intervention between November 2009 and May 2011 (Fig. 1). Twenty-one patients $(8.1 \%)$ discontinued the study. Reasons for discontinuation included withdrawal of consent $(n=11)$, (serious) AEs (SAEs) $(n=5,3$ in the active group and 2 in the control group), patient lost to follow-up $(n=1)$, major protocol deviation $(n=1)$, and 'other' $(n=3)$. Baseline characteristics are summarized in Table 2. The study groups were well matched with regard to all characteristics. The mean baseline MMSE score for the overall study group was 25.0, suggestive of a population with very mild AD.

\section{Primary outcome parameter}

The NTB memory domain data are presented in Fig. 2 and Table 3. The memory domain z-score showed significant differences between the active

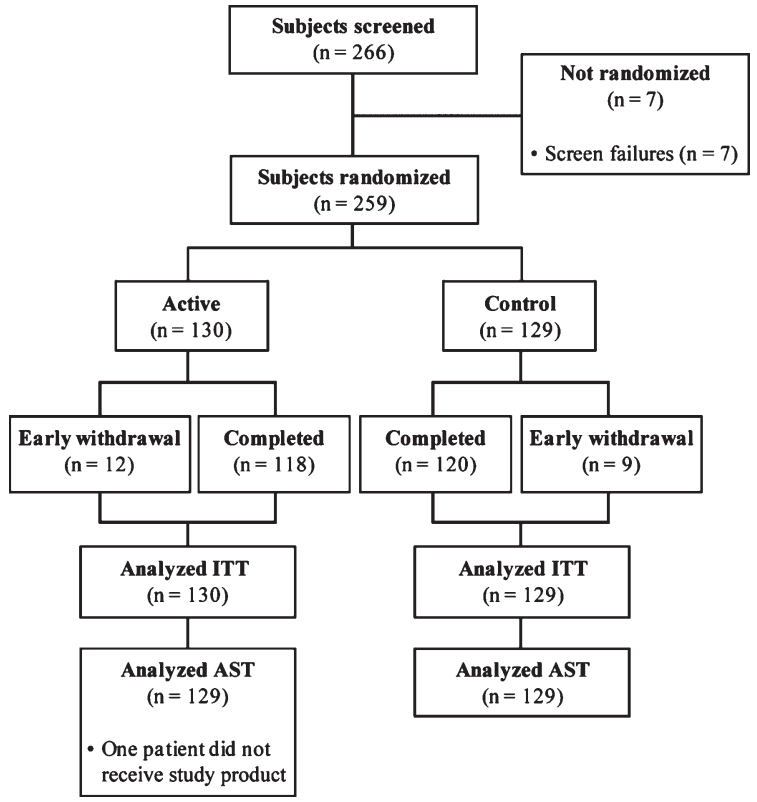

Fig. 1. Patient disposition. AST, all-subjects-treated population; ITT, intent-to-treat population.

Table 2

Baseline demographics and characteristics of the intent-to-treat population

\begin{tabular}{|c|c|c|}
\hline & $\begin{array}{l}\text { Control } \\
(n=129)\end{array}$ & $\begin{array}{l}\text { Active } \\
(n=130)\end{array}$ \\
\hline Male, $n(\%)$ & $64(49.6)$ & $68(52.3)$ \\
\hline Age, years [range] & $73.2(8.4)$ [51-88] & 74.4 (6.9) [55-89] \\
\hline $\begin{array}{l}\text { Body mass index, } \\
\mathrm{kg} / \mathrm{m}^{2}\end{array}$ & $26.7(4.2)$ & $26.1(4.1)$ \\
\hline $\begin{array}{l}\text { Years of education } \\
\text { beyond primary } \\
\text { school }\end{array}$ & $6.6(4.6)$ & $6.5(4.8)$ \\
\hline $\begin{array}{l}\text { Duration of AD since } \\
\text { diagnosis, months, } \\
\text { Median [range] }\end{array}$ & $2.0[0.0-88.0]$ & $1.0[0.0-70.0]$ \\
\hline \multicolumn{3}{|l|}{$\begin{array}{l}\text { Apolipoprotein E } \varepsilon 4 \\
\text { carrier, } n(\%)\end{array}$} \\
\hline No & $58(49.2)$ & $62(51.2)$ \\
\hline Yes & $60(50.8)$ & $59(48.8)$ \\
\hline Unknown & 11 & 9 \\
\hline $\begin{array}{l}\text { Total Mini-Mental } \\
\text { State Examination } \\
\text { score }\end{array}$ & $25.0(2.8)$ & $24.9(2.9)$ \\
\hline
\end{tabular}

and control groups in the trajectory over time during the 24-week intervention period (MMRM, $2 \mathrm{df}$ contrast, $p=0.023$, Cohen's $d$ on 24-week change from baseline scores: $0.21,95 \%$ confidence interval $[-0.06]-[0.49])$. The significance of the difference between the active and control groups in their trajectories over time was primarily driven by the changes 


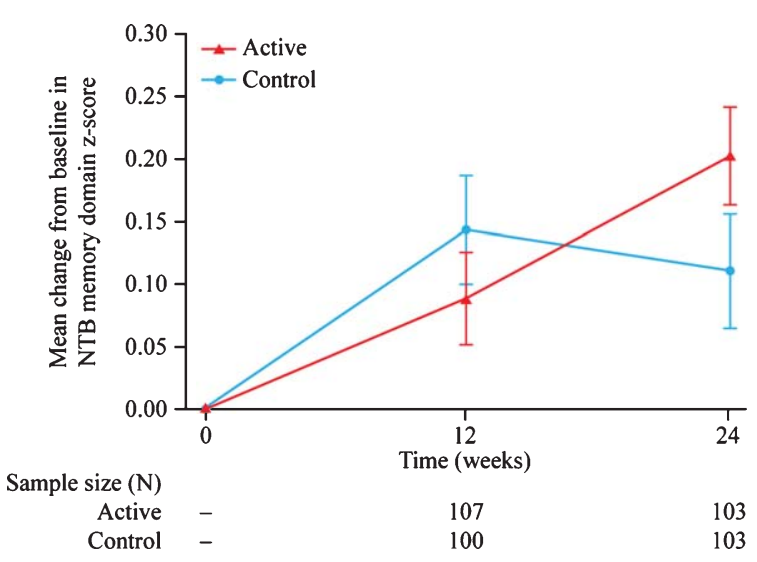

Fig. 2. Mean change from baseline in the Neuropsychological Test Battery (NTB) memory composite score. Error bars represent standard errors. The difference in trajectories over time between active and control groups during the 24-week intervention period: $p=0.023$ (mixed model for repeated measures, 2 degrees of freedom contrast).

from Week 12 to Week 24 (MMRM, $1 \mathrm{df}$ contrast, $p=0.006)$.

Additional sensitivity analyses confirmed the robustness of the significant intervention effect. For example, the effect remained significant in statistical models with different options for the site variance, including site as fixed effect factor, or including an additional random site*treatment interaction effect. In addition, to evaluate the effect of missing NTB items, multiple imputation was used for the calculation of the NTB composite scores in the case of one or two missing NTB items. This confirmed the significant effect on the memory domain score over the 24-week intervention period (MMRM, $2 \mathrm{df}$ contrast, $p=0.032$ ).

\section{Secondary outcome parameters}

There was a trend (MMRM, 2 df contrast, $p=0.053$ ) for an effect on NTB total composite score during the 24-week study period (see Fig. 3 and Table 3). No significant intervention effect on the NTB executive function domain (MMRM, 2 df contrast, $p=0.686$, Fig. 3 and Table 3 ) was observed over 24 weeks. The results of all NTB individual items are summarized in supplementary Table 1.

For the DAD scores (ranging from 0\% [most severe disability] to $100 \%$ [no disability]), a large proportion $(26 \%)$ of patients achieved a maximum score at baseline $($ median $=91.2 \%$ [range $27.5-100 \%$ ], overall study group), resulting in a far from normal distribution. Non-parametric testing of DAD scores did not reveal any significant difference between groups at study endpoint (Mann-Whitney U test, $p=0.361$ ).

EEG data were available for a subset of 179 subjects (86 and 93 from active and control groups, respectively). Parameters on EEG recording and analysis are presented in the Supplementary data, as are baseline characteristics for the subset of subjects for whom EEG data were available (see supplementary Tables 2 and 3). The predefined EEG power and PLI analyses were conducted over all brain areas since no significant interaction effects with brain area were observed. No significant differences between the groups were identified in the relative and absolute power of the different frequency bands. As expected in progressive $\mathrm{AD}$, peak frequency slowed in the control group, which is indicative of cognitive deterioration [24]. The change in peak frequency over

Table 3

Descriptive statistics for NTB composite scores (intent-to-treat population)

\begin{tabular}{|c|c|c|c|}
\hline & $\begin{array}{c}\text { Control } \\
(n=129)\end{array}$ & $\begin{array}{c}\text { Active } \\
(n=130)\end{array}$ & $p$-value ${ }^{\dagger}$ \\
\hline \multicolumn{4}{|l|}{ NTB memory domain z-score } \\
\hline Baseline & $0.078(0.884)[118]$ & $-0.021(0.812)[116]$ & \\
\hline Change baseline - Week 12 & $0.143(0.429)[100]$ & $0.089(0.381)[107]$ & \\
\hline Change baseline - Week 24 & $0.111(0.463)[103]$ & $0.202(0.395)[103]$ & $p=0.090$ \\
\hline 24-week trajectory & & & $p=\mathbf{0 . 0 2 3}$ \\
\hline \multicolumn{4}{|l|}{ NTB executive function domain $\mathrm{z}$-score } \\
\hline Baseline & $0.043(0.779)[113]$ & $0.067(0.734)[113]$ & \\
\hline Change baseline - Week 12 & $0.014(0.351)[97]$ & $0.028(0.337)[100]$ & \\
\hline Change baseline - Week 24 & $0.006(0.323)[99]$ & $0.048(0.333)[93]$ & $p=0.386$ \\
\hline 24-week trajectory & & & $p=0.686$ \\
\hline \multicolumn{4}{|l|}{ NTB total composite z-score } \\
\hline Baseline & $0.115(0.719)[105]$ & $0.029(0.695)[102]$ & \\
\hline Change baseline - Week 12 & $0.075(0.262)[84]$ & $0.063(0.284)[85]$ & \\
\hline Change baseline - Week 24 & $0.035(0.286)[89]$ & $0.120(0.278)[83]$ & $p=0.035$ \\
\hline 24-week trajectory & & & $p=\mathbf{0 . 0 5 3}$ \\
\hline
\end{tabular}

NTB, Neuropsychological Test Battery. Data are presented as mean (standard deviation) [N], unless stated otherwise. ${ }^{\dagger}$ Mixed model for repeated measures with change from baseline as outcome, baseline as covariate. 


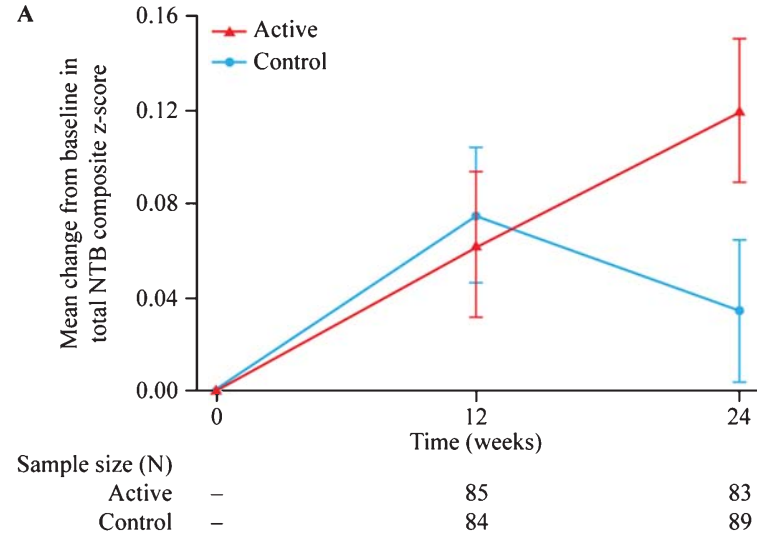

B

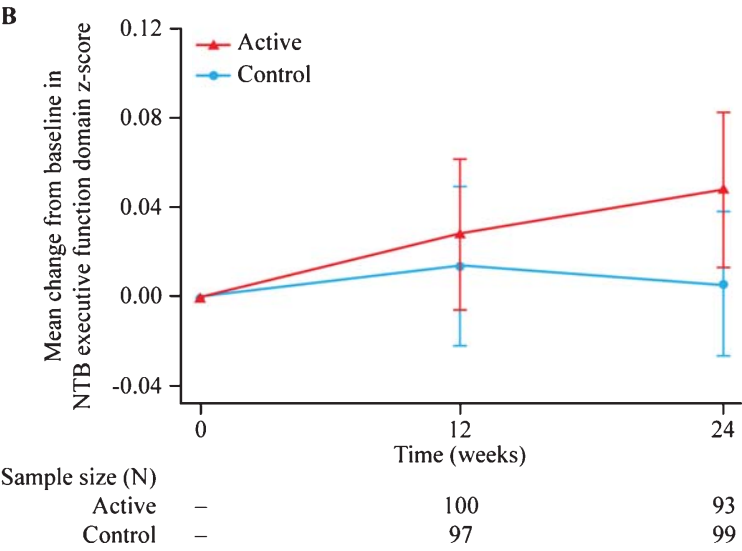

Fig. 3. Mean change from baseline in the (A) Neuropsychological Test Battery (NTB) total composite score and (B) NTB executive function domain score. Error bars represent standard errors; $p$-values represent the difference in trajectories over time between active and control groups during the 24-week intervention period; A) $p=0.053$ (mixed model for repeated measures, 2 degrees of freedom contrast); B) $p=0.686$ (mixed model for repeated measures, 2 degrees of freedom contrast).

time in the active group was significantly different (see supplementary Table 3 and Figure 1). Functional connectivity analysis (PLI) for the delta band revealed a significant difference in trajectory over 24 weeks between study groups in favor of the active group (MMRM, 2 df contrast, $p=0.011$ ) (see Fig. 4). This effect was not observed for the other frequency bands.

Significant biochemical changes of increased erythrocyte DHA and EPA (Mann-Whitney U test, $p<0.001$ ), plasma vitamin $\mathrm{E}$, and decreased plasma homocysteine (Mann-Whitney U test, $p<0.001$ ) were detected in the active group (Fig. 5), indicative of a high adherence to intervention. Indeed, the calculated patient reported compliance during 24 weeks was very high $(96.6 \%$ in the control group and $97.1 \%$ in the

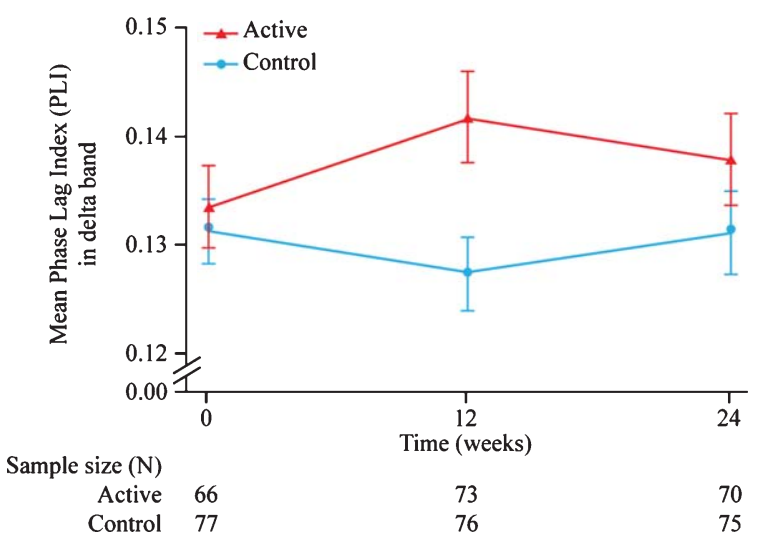

Fig. 4. Mean Phase Lag Index. Error bars represent standard errors. The difference in trajectories over time between active and control groups during the 24-week intervention period: $p=0.011$ (mixed model for repeated measures, 2 degrees of freedom contrast).

active group), with no difference between study groups ( $t$-test, $p=0.536)$.

\section{Safety and tolerability parameters}

In total, 145 patients $(56.2 \%)$ reported at least one AE during the study. Of these, 67 patients $(51.9 \%$; 154 AEs in total) were in the active group, and 78 patients $(60.5 \%$; 185 AEs in total) were in the control group ( $p=0.209$; Fisher's exact test). The majority of reported AEs were assessed as being 'not related' or 'unlikely to be related' to the intervention ( $84.1 \%$ overall; $82.5 \%$ active group; $85.4 \%$ control group), with no significant differences between study groups. The number and proportion of patients experiencing one or more AEs are summarized by body system in Table 4 .

Eighteen SAEs occurred in 16 patients during the study: 11 SAEs in 10 patients in the active group and 7 SAEs in 6 patients in the control group. No SAEs were considered to be related to the study product by the investigator. Four SAEs resulted in premature discontinuation of the study (influenza-like symptoms, cerebrovascular disorder, depression, malaise). No deaths were reported.

No clinically relevant differences between study groups in vital signs and in blood parameters were observed.

\section{DISCUSSION}

The results of this multi-country, multi-center, clinical trial confirm the earlier finding that Souvenaid improved memory performance in drug-naïve patients with mild AD. Similar to previous observations, this 

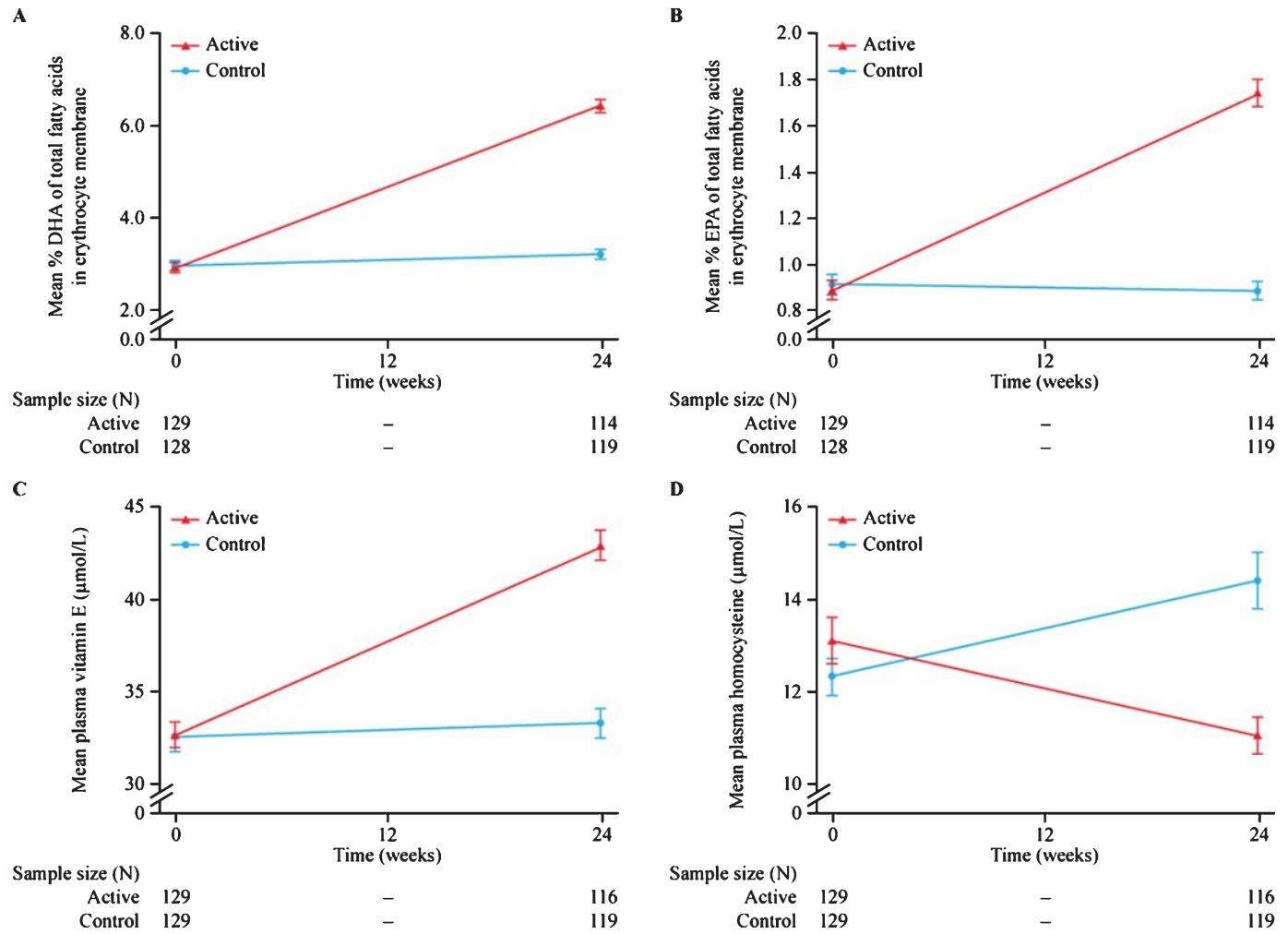

Fig. 5. Mean (A) docosahexaenoic acid (DPA) percentage of fatty acids in erythrocyte membrane, (B) eicosapentaenoic acid (EPA) percentage of fatty acids in erythrocyte membrane, (C) plasma vitamin E levels, and (D) plasma homocysteine. Error bars represent standard errors $p<0.001$ (Mann-Whitney U test).

24-week study showed a positive safety profile and confirmed that Souvenaid is well tolerated. The EEG outcomes in this study demonstrate that there is a significant biological effect that could be interpreted in terms of changes in functional connectivity, supporting the hypothesis that the intervention enhances synapse formation and function. Thus, data from this study suggest that Souvenaid has a beneficial effect on cognitive function in mild $\mathrm{AD}$, most probably by influencing functional connectivity.

Synapse loss is a principal cause of cognitive decline, thus enhancing synapse formation is a compelling and novel interventional target. The ingredients of Souvenaid act together to promote the synthesis of synaptic membranes and, consequently, synaptogenesis [8]. Synapse formation and elimination occurs throughout life and individual brain synapses are presently thought to be permanently remodeled in the adult brain [26]. Souvenaid was specifically designed and intended as a medical food with the action to feed a normal metabolic process by supplying membrane precursors obtained from dietary sources, and nutritional cofactors that enhance the membrane precursor availability. The intention is to address the specific nutritional requirement that patients with $\mathrm{AD}$ may have due to their synapse loss. This nutritional approach has been studied extensively in preclinical studies, and is reviewed elsewhere [8].

AD-related synaptic dysfunction is a pathological process thought to be involved early in the disease process, before the emergence of clinical symptoms [27]. In early $\mathrm{AD}$, (episodic) memory dysfunction is one of the key manifestations, expected to be the most sensitive measure of cognition [19] and thought to be associated with reduction of synaptic contacts [28]. This is in line with our earlier findings in the proofof-concept Souvenir I study, in which Souvenaid was shown to increase the co-primary outcome of memory performance after 12 weeks in mild AD (MMSE 20-26) and in a pre-specified subgroup of very mild AD (MMSE 24-26) as measured by the single WMS-r delayed verbal memory task [15]. The Souvenir II study design was based on these findings and is assessing memory in an early AD population (MMSE $\geq 20$ ) 
Table 4

Number $(\%)$ of patients experiencing one or more adverse events, by affected body system (all-subjects-treated population)*

\begin{tabular}{|c|c|c|c|}
\hline $\begin{array}{l}\text { Body system } \\
\text { Example adverse events }\end{array}$ & $\begin{array}{l}\text { Control } \\
(n=129)\end{array}$ & $\begin{array}{c}\text { Active } \\
(n=129)\end{array}$ & $p$-value ${ }^{\dagger}$ \\
\hline $\begin{array}{l}\text { Body as a whole } \\
\text { Fatigue, influenza-like } \\
\quad \text { symptoms }\end{array}$ & $20(15.5 \%)$ & $11(8.5 \%)$ & 0.125 \\
\hline $\begin{array}{l}\text { Central and peripheral } \\
\text { nervous system disorders } \\
\text { Dizziness, headache }\end{array}$ & $18(14.0 \%)$ & $11(8.5 \%)$ & 0.237 \\
\hline $\begin{array}{l}\text { Gastro-intestinal system } \\
\text { disorders }\end{array}$ & $30(23.3 \%)$ & $22(17.1 \%)$ & 0.277 \\
\hline $\begin{array}{l}\text { Constipation, diarrhea, } \\
\text { flatulence, nausea }\end{array}$ & & & \\
\hline $\begin{array}{l}\text { Metabolic and nutritional } \\
\text { disorders }\end{array}$ & $9(7.0 \%)$ & $13(10.1 \%)$ & 0.505 \\
\hline $\begin{array}{l}\text { Hyperglycemia, weight } \\
\text { increase }\end{array}$ & & & \\
\hline $\begin{array}{l}\text { Musculo-skeletal system } \\
\text { disorders }\end{array}$ & $9(7.0 \%)$ & $10(7.8 \%)$ & 1.000 \\
\hline Arthralgia, neuralgia & & & \\
\hline $\begin{array}{l}\text { Psychiatric disorders } \\
\text { Anxiety, depression, insomnia }\end{array}$ & $16(12.4 \%)$ & $15(11.6 \%)$ & 1.000 \\
\hline $\begin{array}{l}\text { Respiratory system disorders } \\
\text { Pharyngitis, bronchitis }\end{array}$ & $15(11.6 \%)$ & $10(7.8 \%)$ & 0.400 \\
\hline $\begin{array}{l}\text { Skin and appendages } \\
\text { disorders }\end{array}$ & $10(7.8 \%)$ & $4(3.1 \%)$ & 0.168 \\
\hline Rash, skin dry & & & \\
\hline $\begin{array}{l}\text { Other } \\
\text { Fall, surgical intervention }\end{array}$ & $8(6.2 \%)$ & $8(6.2 \%)$ & 1.000 \\
\hline
\end{tabular}

*Only those reported by at least $5 \%$ of patients in either group are shown. Adverse events occurring in less than $5 \%$ of patients were: cardiovascular disorders, hearing and vestibular disorders, heart rate and rhythm disorders, liver and biliary system disorders, myo/endo/pericardial and valve disorders, neoplasm, platelet, bleeding and clotting disorders, red blood cell disorders, reproductive disorders (male), resistance mechanism disorders, urinary system disorders, vascular (extracardiac) disorders, vision disorders. †Fisher's exact test.

using the $a$ priori defined NTB memory domain composite score, derived from five neuropsychological memory tasks.

Due to the different nature of the memory tests in the two studies with Souvenaid, including paragraph recall, word learning, and paired word association, the Souvenir II study extends our understanding of the effect that Souvenaid has on memory performance in patients with mild AD. The use of the NTB memory domain composite score and clustering of its raw memory test scores decreases variation associated with individual tests and helps to improve the robustness of the underlying cognitive constructs $[29,30]$.

The evidence for the degree of cognitive change as measured by the NTB is somewhat limited, which makes it more difficult to relate the memory effects reported here in terms of clinical effectiveness. A previously reported study showed that the mean 12-month
NTB memory domain change from baseline for mildto-moderate $\mathrm{AD}$ patients receiving placebo was -0.17 [20], while the average 12-month NTB change from baseline for patients with mild AD was -0.21 [22]. Another study by Salloway et al. [31] has reported similar NTB changes from baseline during 78 weeks. Even though the NTB composition employed in the Souvenir II study varied slightly from previous studies, the 24-week change from baseline of the NTB memory domain composite score of 0.20 in the active group is in the same order of magnitude, but in the positive direction compared to the decline observed in the placebo groups of these longitudinal studies. The 24-week Souvenir II open-label extension study (Dutch Trial Registration number NTR2571) will provide more data on the NTB memory domain, and further studies are needed to investigate the long-term outcome of Souvenaid intervention.

The EEG signal reflects synchronous activity of many synapses and is therefore a derivative of underlying synaptic function [32]. The increasingly sophisticated tools available for the analysis of EEG signals provide opportunities to study small longitudinal changes, and as such EEG is increasingly valuable as an outcome measure in studies on $\mathrm{AD}$ and other dementias [33-36]. Quantitative frequency analysis and analysis of functional connectivity have shown slowing of the peak frequency and decreased functional connectivity between brain regions in patients with $\mathrm{AD}$ compared with controls [37]. The present findings of a significant difference in peak frequency and functional connectivity in the delta band over the 24-week intervention period between the active and control groups suggest preserved and even increased synaptic function in the active group. AD-related synaptic dysfunction is a pathological biomarker believed to rise before functional abnormalities manifest [27]. To our knowledge this study is the first to provide evidence for the hypothesis that supporting synaptic function in the mild stage of $\mathrm{AD}$ by using a nutritional intervention may be related to improved memory performance. This provides the impetus for further investigations using even more sophisticated techniques to study connectivity, such as magnetoencephalography.

The favorable safety profile of the nutritional intervention confirmed the hypothesis that the intervention would be well tolerated. AEs were consistent with those expected in an elderly population with mild AD. There were no differences between study groups in discontinuations due to (S)AEs, and none of the SAEs were considered to be related to the use of the study 
product. Safety data were in line with those reported for the previous proof-of-concept study with Souvenaid [15]. The favorable safety profile and risk-benefit ratio, and mechanism of action make Souvenaid a promising candidate for further clinical investigation in the earlier stages of the AD spectrum, especially considering the disappointing results of single-nutrient intervention in many clinical studies [38].

There are some limitations to the study that should be considered when interpreting the results. Notably, the study was performed in an early AD population, and while the probable AD diagnosis was made according to the NINCDS-ADRDA criteria, no biomarker evidence was utilized for diagnosis. Also, the study population was moderate in size when compared to other AD clinical trials. Despite this, significant intervention effects were clearly identified and larger studies with more frequent assessments may reveal additional intervention effects. Secondly, an apparent placebo effect was observed after 12 weeks (the first assessments after baseline) for the overall NTB memory domain and various other NTB parameters. This may be a genuine placebo effect, or partly due to other factors such as learning/familiarity with the tests themselves, which again given the mildly affected state of the patients may have happened. In future studies, using two baseline scores and parallel versions of tests may overcome this [39]. Third, although no effect was observed on the overall executive function domain, dissociation between cognitive domains linked to the mechanism of action is not uncommon, and has been reported in previous studies utilizing the NTB as an outcome measure [20,40]. Similarly, no effect was shown on the DAD, which may be due to the high percentage of patients showing a maximum DAD score at baseline, which in turn may be due to the very mild nature of $\mathrm{AD}$ in this study population. In addition, it is less conventional in an AD clinical trial to take the response profile from a MMRM analysis as the primary approach to identify an intervention effect. Nevertheless, this approach is particularly beneficial when the functional form of the response profiles is difficult to anticipate, and linear time trends may not adequately describe the response. Therefore, we pre-defined "trajectory of change" as our primary indicator of treatment effect. Finally, while a 24 -week double-blind study has been typical for clinical trials in $\mathrm{AD}$, and appropriate in view of ethical considerations in a drug-naive population, it may be short given that AD is a chronic disease. Further studies are therefore warranted to investigate the longer-term outcome of Souvenaid intervention and to broaden our understanding of how the changes in functional connectivity over time for the delta band and mean peak frequency are related to clinical outcomes and other characteristics of brain network organization. These studies should be performed both with and without concomitant $\mathrm{AD}$ medications to reflect real-life clinical practice.

In conclusion, this study confirms that Souvenaid is well tolerated and improves memory performance. The testing of the underlying hypothesis has now made significant advances, offering hope towards a future management strategy directed at one of the major pathological manifestations or early AD. Our results warrant further investigation of the clinical potential of Souvenaid in preclinical or clinical conditions characterized by synaptic loss, in particular AD.

\section{ACKNOWLEDGMENTS}

Study design and planning were carried out in conjunction with the sponsor, Danone Research BV, on behalf of Nutricia Advanced Medical Nutrition, Danone's specialized healthcare unit. The sponsor also provided the study products and funding for the research and data collection. The Souvenir II study was further supported by the NL Food \& Nutrition Delta project, FND $N^{\circ} 10003$. Data analysis was conducted by staff of Danone Research and an outside statistician (JWR Twisk) independently and again by staff at Rush Alzheimer's Disease Center (S Leurgans, RC Shah, DA Bennett, W Fan) who received the whole data set and preformed a statistical analysis blinded to study treatment on the primary outcome measure. We thank Dr ECW van Straaten (Department of Clinical Neurophysiology, VU University Medical Center, Amsterdam, The Netherlands) for help in analyzing and interpreting the EEG data. All authors had full access to the study data. The corresponding author had final responsibility for the decision to submit for publication. We sincerely thank the patients and their caregivers for their participation in the study.

Authors' disclosures available online (http://www.jalz.com/disclosures/view.php?id=1376).

\section{CONTRIBUTORS}

Investigators: The Netherlands: P Scheltens, F Verhey, MGM Olde Rikkert, FH Bouwman, EACM Sanders, PLJ Dautzenberg, WMW Sipers, D van Asselt, M Stevens; Belgium: PP De Deyn, P Tack, P Bourgeois, MFJ Vandewoude, E Mulleners; Germany: 
CAF von Arnim, R Horn, H-J Gertz, J Schröder, K-C Steinwachs; Spain: R Blesa, PG Gil, MR Boada. Italy: E Scarpini, P Mecocci, G Rodriguez; France: B. Vellas, P-J Ousset, MM Vercelletto, MPM Ceccaldi.

Steering committee: P Scheltens (co-ordinating investigator), DA Bennett, MJ van der Mooren, PJGH Kamphuis, RC Shah.

Independent data monitoring committee: IG McKeith, K Rockwood, JWR Twisk, R Witkamp.

\section{REFERENCES}

[1] Selkoe DJ (2002) Alzheimer's disease is a synaptic failure. Science 298, 789-791.

[2] Terry RD, Masliah E, Salmon DP, Butters N, DeTeresa R, Hill R, Hansen LA, Katzman R (1991) Physical basis of cognitive alterations in Alzheimer's disease: Synapse loss is the major correlate of cognitive impairment. Ann Neurol 30, 572-580.

[3] DeKosky ST, Scheff SW (1990) Synapse loss in frontal cortex biopsies in Alzheimer's disease: Correlation with cognitive severity. Ann Neurol 27, 457-464.

[4] Nitsch RM, Blusztajn JK, Pittas AG, Slack BE, Growdon JH, Wurtman RJ (1992) Evidence for a membrane defect in Alzheimer disease brain. Proc Natl Acad Sci U S A 89, 1671-1675.

[5] Pettegrew JW, Panchalingam K, Hamilton RL, McClure RJ (2001) Brain membrane phospholipid alterations in Alzheimer's disease. Neurochem Res 26, 771-782.

[6] Damoiseaux JS, Prater KE, Miller BL, Greicius MD (2012) Functional connectivity tracks clinical deterioration in Alzheimer's disease. Neurobiol Aging 33, 828 e19-e30.

[7] Stam CJ, de Haan W, Daffertshofer A, Jones BF, Manshanden I, van Cappellen van Walsum AM, Montez T, Verbunt JP, de Munck JC, van Dijk BW, Berendse HW, Scheltens P (2009) Graph theoretical analysis of magnetoencephalographic functional connectivity in Alzheimer's disease. Brain 132, 213-224.

[8] Wurtman RJ, Cansev M, Sakamoto T, Ulus IH (2009) Use of phosphatide precursors to promote synaptogenesis. Annu Rev Nutr 29, 59-87.

[9] Pooler AM, Guez DH, Benedictus R, Wurtman RJ (2005) Uridine enhances neurite outgrowth in nerve growth factordifferentiated PC12 [corrected]. Neuroscience 134, 207-214.

[10] Sakamoto T, Cansev M, Wurtman RJ (2007) Oral supplementation with docosahexaenoic acid and uridine- $5^{\prime}$ monophosphate increases dendritic spine density in adult gerbil hippocampus. Brain Res 1182, 50-59.

[11] van Wijk N, Watkins CJ, Bohlke M, Maher TJ, Hageman RJ, Kamphuis PJ, Broersen LM, Wurtman RJ (2012) Plasma choline concentration varies with different dietary levels of vitamins B6, B12 and folic acid in rats maintained on cholineadequate diets. Br J Nutr 107, 1408-1412.

[12] de Wilde MC, Penke B, van der Beek EM, Kuipers AA, Kamphuis PJ, Broersen LM (2011) Neuroprotective effects of a specific multi-nutrient intervention against Abeta42-induced toxicity in rats. J Alzheimers Dis 27, 327-339.

[13] de Bruin NM, Kiliaan AJ, de Wilde MC, Broersen LM (2003) Combined uridine and choline administration improves cognitive deficits in spontaneously hypertensive rats. Neurobiol Learn Mem 80, 63-79.
[14] Kamphuis PJ, Scheltens P (2010) Can nutrients prevent or delay onset of Alzheimer's disease? J Alzheimers Dis 20, 765775 .

[15] Scheltens P, Kamphuis PJ, Verhey FR, Olde Rikkert MG, Wurtman RJ, Wilkinson D, Twisk JW, Kurz A (2010) Efficacy of a medical food in mild Alzheimer's disease: A randomized, controlled trial. Alzheimers Dement 6, 1-10 e1.

[16] Stam CJ (2010) Characterization of anatomical and functional connectivity in the brain: A complex networks perspective. Int J Psychophys 77, 186-194.

[17] Vellas B, Andrieu S, Sampaio C, Coley N, Wilcock G (2008) Endpoints for trials in Alzheimer's disease: A European task force consensus. Lancet Neurol 7, 436-450.

[18] Kamphuis PJ, Verhey FR, Olde Rikkert MG, Twisk JW, Swinkels SH, Scheltens P (2011) Efficacy of a medical food on cognition in Alzheimer's disease: Results from secondary analyses of a randomized, controlled trial. J Nutr Health Aging 15, 720-724.

[19] Jack CR Jr, Knopman DS, Jagust WJ, Shaw LM, Aisen PS, Weiner MW, Petersen RC, Trojanowski JQ (2010) Hypothetical model of dynamic biomarkers of the Alzheimer's pathological cascade. Lancet Neurol 9, 119-128.

[20] Gilman S, Koller M, Black RS, Jenkins L, Griffith SG, Fox NC, Eisner L, Kirby L, Rovira MB, Forette F, Orgogozo JM (2005) Clinical effects of Abeta immunization (AN1792) in patients with $\mathrm{AD}$ in an interrupted trial. Neurology 64, 15531562 .

[21] McKhann G, Drachman D, Folstein M, Katzman R, Price D, Stadlan EM (1984) Clinical diagnosis of Alzheimer's disease: Report of the NINCDS-ADRDA Work Group under the auspices of Department of Health and Human Services Task Force on Alzheimer's Disease. Neurology 34, 939944.

[22] Harrison J, Minassian SL, Jenkins L, Black RS, Koller M, Grundman M (2007) A neuropsychological test battery for use in Alzheimer disease clinical trials. Arch Neurol 64, 13231329.

[23] Gelinas I, Gauthier L, McIntyre M, Gauthier S (1999) Development of a functional measure for persons with Alzheimer's disease: The disability assessment for dementia. Am J Occup Ther 53, 471-481.

[24] Klassen BT, Hentz JG, Shill HA, Driver-Dunckley E, Evidente VG, Sabbagh MN, Adler CH, Caviness JN (2011) Quantitative EEG as a predictive biomarker for Parkinson disease dementia. Neurology 77, 118-124.

[25] Stam CJ, Nolte G, Daffertshofer A (2007) Phase lag index: Assessment of functional connectivity from multi channel EEG and MEG with diminished bias from common sources. Hum Brain Mapp 28, 1178-1193.

[26] Lardi-Studler B, Fritschy JM (2007) Matching of pre- and postsynaptic specializations during synaptogenesis. Neuroscientist 13, 115-126.

[27] Sperling RA, Aisen PS, Beckett LA, Bennett DA, Craft S, Fagan AM, Iwatsubo T, Jack CR Jr, Kaye J, Montine TJ, Park DC, Reiman EM, Rowe CC, Siemers E, Stern Y, Yaffe K, Carrillo MC, Thies B, Morrison-Bogorad M, Wagster MV, Phelps CH (2011) Toward defining the preclinical stages of Alzheimer's disease: Recommendations from the National Institute on Aging-Alzheimer's Association workgroups on diagnostic guidelines for Alzheimer's disease. Alzheimers Dement 7, 280-292.

[28] Scheff SW, Price DA, Schmitt FA, Mufson EJ (2006) Hippocampal synaptic loss in early Alzheimer's disease and mild cognitive impairment. Neurobiol Aging 27, 13721384. 
[29] van de Rest O, Geleijnse JM, Kok FJ, van Staveren WA, Dullemeijer C, Olde Rikkert MG, Beekman AT, de Groot CP (2008) Effect of fish oil on cognitive performance in older subjects: A randomized, controlled trial. Neurology 71, 430-438.

[30] Durga J, van Boxtel MP, Schouten EG, Kok FJ, Jolles J, Katan MB, Verhoef P (2007) Effect of 3-year folic acid supplementation on cognitive function in older adults in the FACIT trial: A randomised, double blind, controlled trial. Lancet $\mathbf{3 6 9}$, 208-216.

[31] Salloway S, Sperling R, Keren R, Porsteinsson AP, van Dyck $\mathrm{CH}$, Tariot PN, Gilman S, Arnold D, Abushakra S, Hernandez C, Crans G, Liang E, Quinn G, Bairu M, Pastrak A, Cedarbaum JM, ELND005-AD201, Investigators (2011) A phase 2 randomized trial of ELND005, scyllo-inositol, in mild to moderate Alzheimer disease. Neurology 77, 1253-1262.

[32] Siegel M, Donner TH, Engel AK (2012) Spectral fingerprints of large-scale neuronal interactions. Nat Rev Neurosci 13, 121-134.

[33] Ramakers GJ (2005) Neuronal network formation in human cerebral cortex. Prog Brain Res 147, 1-14.

[34] Coben LA, Danziger W, Storandt M (1985) A longitudinal EEG study of mild senile dementia of Alzheimer type: Changes at 1 year and at 2.5 years. Electroencephalogr Clin Neurophysiol 61, 101-112.

[35] van der Hiele K, Vein AA, Reijntjes RH, Westendorp RG, Bollen EL, van Buchem MA, van Dijk JG, Middelkoop HA (2007) EEG correlates in the spectrum of cognitive decline. Clin Neurophysiol 118, 1931-1939.
[36] Stam CJ, Jones BF, Nolte G, Breakspear M, Scheltens P (2007) Small-world networks and functional connectivity in Alzheimer's disease. Cereb Cortex 17, 92-99.

[37] Stam CJ (2011) Dementia and EEG. In Niedermeyer's Electroencephalography Basic Principles, Clinical Applications and Related fields, 6th ed., Schomer D, FH Lopes da Silva (Eds). Lippincott Williams and Wilkins, Philadelphia, PA, pp. 375-393.

[38] de Wilde MC, Kamphuis PJ, Sijben JW, Scheltens P (2011) Utility of imaging for nutritional intervention studies in Alzheimer's disease. Eur J Pharmacol 668(Suppl 1), S59S69.

[39] Ferris SH, Lucca U, Mohs R, Dubois B, Wesnes K, Erzigkeit H, Geldmacher D, Bodick N (1997) Objective psychometric tests in clinical trials of dementia drugs. Position paper from the International Working Group on Harmonization of Dementia Drug Guidelines. Alzheimer Dis Assoc Disord 11(Suppl 3), 34-38.

[40] Lannfelt L, Blennow K, Zetterberg H, Batsman S, Ames D, Harrison J, Masters CL, Targum S, Bush AI, Murdoch R, Wilson J, Ritchie CW, PBT2-201-EURO study group (2008) Safety, efficacy, and biomarker findings of PBT2 in targeting Abeta as a modifying therapy for Alzheimer's disease: A phase IIa, double-blind, randomised, placebo-controlled trial. Lancet Neurol 7, 779-786. 